\title{
O NOME DA ROSA: ECOS BORGIANOS
}

\author{
Denise A.D.Guimarães ${ }^{*}$
}

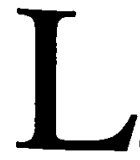

er intertextualmente é ver no texto literário o local de conflito, o espaço onde se inserem dialeticamente estruturas plurais. $O$ diálogo entre os textos é um processo complexo; uma espécie de montagem em progressiva função estética a scr decodificada, decifrada, recriada na instância de leitura.

Nesta espécie de "leitura-montagem", também dialógica, o intertexto fornece as pistas, mas não as saidas a serem deflagradas no processo de recepção.

Julia Kristeva diz que os textos da modernidade constroem-se pela absorçāo e destruição simultâneas de outros textos do espaço intertextual. Neste processo de produtividade, visto por Bakhtin como tessitura polifônica, o discurso literário envolve um cruzamento de vários textos, um diảlogo em direção ao "corpus" literário anterior ou contemporâneo.

Tanto O nome da rosa, de 1980, quanto os textos de Jorge Luis Borges, bem anteriores, apresentam fortes marcas intertextuais. Ao aproximá-los, este estudo pretende captar certos ecos borgianos no romance de Umberto Eco.

Semioticista, Umberto Eco tem consciência da peculiar riqueza formal e semântica da "memória" do sistema semiótico literário; da sua capacidade de produzir inesgotávcis significados. Sob a estrutura de um

- Universidade Federal do Paraná 
determinado texto, antes e debaixo dele, existe uma espécie de palimpsesto, capaz de aflorar explicita ou implicitamente na sua estrutura, interferindo na sua estratificação.

Utilizando-se das alusōes, das metáforas, dos recursos, palimpsésticos, Eco disseminou ao longo de seu romance - um intertexto por excelência - uma série de indices para a compreensão mais profunda de sua estrutura e mesmo para sua interpretação. Seu enunciado remete a outros, tornando legiveis vários outros discursos. Vale lembrar, neste caso, a noção de circularidade, tão explorada por Borges. Pela circularidade, muitas vezes labiríntica, a multiplicidade dos caminhos intertextuais faz do texto uma escritura complexa, opaca, infinita...

Ler intertextualmente $O$ nome da rosa é tentar encontrar os indices conscientes ou inconscientes de um complicado processo de cnunciação; é tentar descobrir a sua técnica de produção.

Sendo um romance único e outros ao mesmo tempo, seu sentido intertextual não pode ser captado sinteticamente mas analiticamente, para que se possa perceber a convivência dos vários textos numa única estrutura textual sem que eles se destruam mutuamente. A linguagem segunda, a do romance de Eco, trabalha subordinativamente suas marcas referenciais. Dai o importante papel da hipotaxe na constituição de um complexo sintagma intertextual: uma totalidade nova a exigir uma investigação de seu diálogo com outros textos. As marcas semanticas que aproximam dois ou mais textos são indices que se espalham pelo texto segundo e exigem uma coordenação. A leitura intertextual não apenas recolhe tais índices, mas justapōe os textos correlacionados para verificar similitudes e diferenças. Este é o momento da percepção das relaçōes, das vozes que se articulam entre os textos e que apontam para uma direção de leitura.

Percorrendo o caminho que vai da razão para a imaginação, cabe ao leitor captar metonimicamente os significados primeiros para, em seguida, trabalhá-los dialogicamente. Desse modo poderá preencher paradigmaticamente as vigas-mestras da narrativa, apreendendo as grandes metáforas intertextuais.

Os caminhos para o intertexto foram abertos pelos processos e técnicas de composição das artes visuais, como a colagem da pintura cubista, pela polifonia musical ou pela montagem no cinema.

No programa de televisāo "Conexāo Internacional", em 1988, Umberto Eco disse que $O$ nome da rosa é uma enorme colagem. A valorização da colagem como procedimento esteticamente produtivo fôra feita inúmeras vezes antes pelo autor. Em 1975, num estudo sobre o filme "Casablanca" 
diz: "Casablanca" não é um filme, é muitos filmes, uma antologia... Nele estão todos os arquétipos, a citação de mil outros filmes, e cada ator refez um papel desempenhado outras vezes, jogando sobre o espectador a ressonância da intertextualidade. E neste cruzamento de clichês que "falam entre si e celcbram uma festa de reencontro", Eco entrevê uma "suspeita de sublime". 1

Pode-se perceber com que prazer o autor comporta-se como "bricoleur" em seu romance, recortando textos anteriores para reorganizálos num universo sígnico peculiar. Considerando que a bricolage da vanguarda é declarada, por aspirar à descoberta de novas dimensões dos fatos, Eco enfatiza: "A arte, accitando 'bricolar' procura sair de uma situação em que tudo parece já dito." ${ }^{2}$

Em termos teóricos, o desenvolvimento das teorias da intertextualidade levou a uma revisão dos conceitos de imitação e de influência, uma vez que todas as possibilidades de significação do texto visto como produção apóiam-se $\mathrm{cm}$ infinitas formas de referéncia.

O fato de uma obra de arte tomar outra como modelo, uma "imitatio" regicla pela "ars", desde que motivada pelo descjo de superaşäo, foi reconhecida pelos clássicos como procedimento legítimo.

No final do século XVIII, a "teoria do gênio" instaurou a preocupação com a originalidade, seja nos temas, nas formas ou nas técnicas. Acentuou-se o conflito entre imitar e ser original.Plágio, pastiche, passaram a ser palavras muitos usadas, no sentido da recusa de modelos.

Depois das vanguardas de nosso século, a vertente estética da paródia, ou mesmo a da apropriaçāo, recolocou a questão no centro das preocupações com os textos de estrutura complexa. Percebeu-se como procedimento válido e atual, o servir-se de outro texto como pretexto para a criação artística. O texto anterior é modificado, redimensionado e a obra nova apresenta os indices do procedimento intertextual. Trata-se portanto de uma atualização em termos de imagens estéticas, de uma procura da linguagem do nosso tempo para dizer o já dito. Validado pela crítica e pelas teorias mais recentes, tal procedimento não deve ser confundido com a imilação pura e simples, com o plágio, ou com a mera cópia. O próprio sentido do terno paródia deve ser repensado como exercício da linguagem p. 268

I:CO, Unberto. Viagem na irrealidade cotidiana. Rio de Janeiro: Nova lironteira, 1984 -.

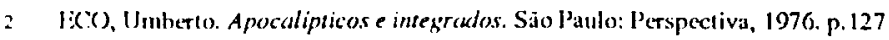


que se dobra sobre si mesma, num jogo de espelhos, numa alquimia de recursos formais e estilísticos; não mais sinônimos de pastiche.

"O prazer da imitação, já o sabiam os antigos, é um dos mais inatos à alma humana", diz Umberto Eco. ${ }^{3}$ Valorizada em seu caráter consciente, a intertextualidade pode ser vista como uma espécie de osmose, uma penetração lenta, uma identificação com elementos expressivos da obra anterior ou do "corpus" considerado.

Deve-se repensar também a questäo das influências. Em arte, "fazer escola" significa exercer influência sobre outros criadores. Umberto Eco explica que a obra de arte pode "fazer escola" de duas maneiras:

1) "Propondo-se como exemplo concreto de um modo de formar, inspirado no qual outro arista pode também elaborar modos operacionais próprios e originais.

2) Oferecendo, a toda uma tradição de fruidores, estilemas também usáveis separadamente do contexto original, e todavia sempre capazes de evocar, embora isolados, as características desse contexto(...) carregando, sem perceber o novo contexto de uma parte de aprovação tributada ao contexto original."

E completa: "No caso de estilemas afins - teria um autor o achado de outro em mente ao escrever suas páginas? Mesmo que não, a analogia existe e deve ser sublinhada. ${ }^{4}$

Nas palavras do autor, tiradas de livros diferentes, e portanto expressando momentos diversos de reflexảo, percebemos o novo enfoque dado à questão da influência. Inspirar-se em um autor nem sempre é negativo; ao contrário pode ser altamente produtivo e mostrar que o artista atual é um fruidor da obra anterior.

Já Roland Barthes, com seu conceito de escritura como texto plural, via na possibilidade de reescrever os livros a única saida para o impasse das palavras no nosso tempo. Tudo já foi dito e o esgotamento da linguagem desloca para o terreno da citação, do diálogo entre textos, as possibilidades do dizivel.

Borges, com sabedoria, dizia não saber se fora ele ou outro quem escrevera determinada página, $\mathrm{e}$ isto não tinha a menor importância.

Umberto Eco, sabedor destas e outras coisas, ciente dos mecanismos pelos quais um grande autor faz escola ou exerce influência sobre outros,

3 FCO, Umberto. Viagem. p.58

4 ld. Aproalipticos... p. 113 
leva o leitor, por exemplo, a uma releitura de Conan Doyle ou de Jorge Luis Borges, através de seu romance. Percebendo os estilemas afins que inserem Eco numa tradição de fruidores do grande escritor argentino, o leitor conscientiza-se do tributo que the é prestado, num texto impregnado pela aprovação escritural aos motivos e temas, técnicas e processos narrativos do universo borgiano.

Para Freud, o texto literário não cria propriamente, e sim efetua a recomposição de elementos já existentes, tendo por base a invenção. Bakhtin, ao salientar que a palavra já vem impregnada da voz do outro, nunca é recebida de forma neutra pelo falante, diz: "No contexto dele, a palavra deriva de outro contexto, é impregnada de interpretações de outros. $O$ próprio pensamento dele já encontra a palavra povoada. ${ }^{5}$

Borges, por sua vez, enfatiza sua noção da obra literária como uma deliberada e bem sucedida apropriação de palavras alheias. No planela inventado de seu conto "Tlón, Uqbar, Orbis Tertius", : "... não existe o conceito de plágio: estabelecem-se que todas as obras são obra de um só autor, que é intemporal e anónimo".

Lemos em Bakhtin que um autor "pode usar o discurso de um outro para os seus fins pelo mesmo caminho que imprime orientação significativa ao discurso que já tem sua própria orientação e a conserva. Neste caso, este discurso, conforme a tarefa, deve ser sentido como o de um outro. Em um só discurso ocorrem duas orientações significativas, duas vozes. Assim é o discurso parodístico, assim é a estilização, assim é o skaz estilizado." E ainda: "As palavras do outro, introduzidas na nossa fala, são revestidas inevitavelmente de algo novo, de nossa compreensão e de nossa avaliação, isto $\dot{c}$, tornam-se bivocais. O nosso discurso da vida prática está cheio de palavras dos outros. Com algumas delas fundimos inteiramente nossa voz, esquecendo-nos de quem são; com outras, reforçamos as nossas próprias palavras, aceitando aquelas como autorizadas por nós; por último, revestimos terceiras das nossas próprias intenções, que são estranhas e hostis a elas." 6

Lembremos Borges: "Entende-se ser honroso que um livro atual derive de um antigo."

Ou ainda: "... essas $\mathrm{e}$ outras ambiguas analogias podem significar a

5 BAKHIIN, Miktail. Problemas da poética de Dostoievski. Rio de Janeiro: IDd. Forense-Universitaria, 1981. p. 176

$6 \quad$ ihid. p. 169 
identidade do buscado e do buscador; também podem significar que este influi naquele. ${ }^{7}$

Umberto Eco, por sua vez, insistindo que "os livros falam entre si", considera que a arte não é sistemática, mas cumulativa e compositiva, tanto em nossa era como na medieval:

"... hoje como então, coexiste o experimento elitista refinado com a grande empresa de divulgaçāo popular, com intercâmbios e empréstimos recíprocos e contínuos." ${ }^{8}$

Extremamente consciente do papel da intertextualidade em seu romance, Eco, no seu "Pós-escrito a $O$ nome da rosa", explica:

"Quando a obra está sendo feita, o diálogo é duplo. Há o diálogo entre o tex to e todos os outros tex tos escritos antes (só se fazem livros sobre outros livros e em torno de outros livros) e há o diálogo entre o autor e seu leitor modelo." 9

Ao narrar o processo de composição da cena de amor na cozinha, explicita o processo intertextual:

"É claro que a cena de amor na cozinha é toda construída com citações de textos religiosos, desde o "O Cântico dos Cânticos" a São Bernardo e Jean de Fecamp, ou Santa Hildegarda de Bringen. Mesmo quem não tem prática de mística medieval, mas um pouco de ouvido, percebe isso. Mas quando alguém me pergunta agora de quem são as citações e onde termina uma e começa outra, eu não estou mais em condição de dizê-lo.

De fato eu tinha dezenas e dezenas de fichas com todos os textos, às vezes páginas de livros e inúmeras fotocopias, muito mais do que usei. Mas, quando escrevi a cena, escrevi-a de um jato (só depois é que a poli, como se passasse por cima um verniz homogeneizante, a fim de que as suturas ficassem menos visiveis." 10

O autor afirma que o problema da escritura "resolve-se na escrivaninha, interrogando-se a matéria sobre a qual se trabalha - matéria que possui suas próprias leis naturais, mas que ao mesmo tempo traz consigo a lembrança da cultura de que está embebida (o eco da intertextualidade)." ${ }^{11}$

S0) p. ${ }^{7}$ BORGES, Jorge Luis. Ficções. São Paulo: Abril Cultural, 1972 (Imortais da Literatura,

8 ECO, Umberto. Viagem... p. 97

9 Id. Pós-escrito a "O norne da rosa". Ric de Janeiro: Nova Fronteira 1985. p.40

10 ibid. p. $38-9$

11 ibid. p. 13 

(1941):

Confrontemos com um trecho de Borges, no Prólogo de Fiç̧ōes

"Não sou eu o primeiro autor da narrativa A Biblioteca de Babel. Os curiosos de sua história e de sua pré-história podem examinar certa página do número 59 de SUR, que registra os nomes heterogêneos de Leucipo e de Lasswitz, de Lewis Carroll e de Aristóteles. "... Meu procedimento é simular que estes livros já existem e apresentar um resumo, um comentário."(...)"Mais razoável, incpto, ocioso, preferi a escrita de notas sobre livros imaginários."

Tanto as noções teóricas comentadas anteriormente, quando os conceitos emitidos pelos autores ora cotejados, lembram o recurso tipicamente borgiano da "mise-en-abyme", aquela perspectiva vertiginosa de textos que remetem a outros textos, que remetem a outros textos...

Sob esta perspectiva, passo a analisar a introdução do romance de Eco "Um manuscrito, naturalmente."

O termo "naturalmente", impregnado inferências metalingüisticas, já direciona a leitura para um tipo de ficção extremamente conhecida, onde um manuscrito misteriosamente encontrado funciona como mola propulsora para o desenvolvimento de uma intrincada trama.

Em primeiro lugar, ressalto o procedimento borgiano do escritor italiano, na referida introdução do romance, ao efetuar citações bibliográficas e biográficas, numa deliberada confusão entre dados reais e ficticios.

"A 16 de agosto de 1968, veio parar em minhas mãos um livro devido à pena de um certo abade Vallet, 'Le manuscript de Dom Adson de Melk, traduit en français d’après l'edition de Dom J. Mabillon (Aux Presses de l'Abbaye de la Source, Paris, $1842 . .^{\prime \prime 2}$

Observe-se a data completa e os dados precisos sobre o livro, que são acrescidos da seguinte informação: "O livro assegurava estar reproduzindo fielmente um manuscrito do século XIV, encontrado por sua vez no mosteiro de Melk pelo grande erudito seiscentista, a quem tanto se deve pela história da ordem beneditina."

Tantas e tão detalhadas informações objetivam justamente colocar ao) leitor como indiscutivel a existência do referido livro.

12 I:( (), Unubeto. O nome da rosa. $7 \mathrm{ed}$. Rio de Janciro: Nova Fronteira, 1983.p. $11 . \wedge$ partir daqui imalicarci apenas a página da presente ediçáo, entre parênteses, após a cilaçáo de irechos do romance. 
Borges utiliza-se obsessivamente de tais recursos. Vejamos, por exemplo no conto "Tlon, Uqbar, Orbis Tertius":

"Devo à conjunção de um espelho e de uma enciclopédia o descobrimento de Uqbar. O espelho inquietava o fundo de um corredor numa quinta da Rua Gaona, em Ramos Mejia; a enciclopédia falazmente se chama THE ANGLO-AMERICAN CYCLOPAEDIA (New York, 1917) e é uma reimpressão literal, mas também tardia, da ENCYCLOPAEDIA BRITANNICA de 1902." ${ }^{13}$

E continua alguns parágrafos adiante: "Em setembro de 1937 (nós não estávamos no hotel), Herbert Ashe morreu da ruptura de um ancurisma. Dias antes recebera do Brasil um pacote lacrado e registrado. Era um livro $\mathrm{cm}$ oitava maior. Pus-me a folheá-lo e senti uma ligeira vertigem de assombro que nāo descreverei (...) O livro estava redigido $\mathrm{cm}$ inglês e o compunham 1001 páginas." (p.21)

Percebemos que o fato idêntico de um livro misterioso e raro chegar às mãos do narrador é explorado pelos dois autores, com a preocupação de fornecer uma série de informaçōes sobre o mesmo; e cujo objetivo é tornar a história verossímil.

Voltando a Eco: "Como o leitor terá imaginado, na biblioteca do mostciro nāo encontrei traços do manuscrito de Adson." (p.11)

E agora Borges: "Entrou e consultou o volume XLVI. Naturalmente, não encontrou o menor indício de Uqbar." (p.19)

Creio ser desnecessário qualquer comentário a respeito.

No romance de Eco, após a perda do livro, detalhadamente narrada e justificada, tanto no tempo quanto geograficamente, o narrador diz:

"Das poucas noticias que tinha retirado do livro francês, sobrava-me a referēncia à fonte, excepcionalmente minuciosa e precisa." Segue-se uma longa referencia.

E continua: "Encontrei logo os VETERA ANALECTA na biblioteca Sainte Geneviève, mas, para minha grande surpresa, a edição descoberta discordava em dois particulares: primeiro o editor que era Montalant, ad Ripam P.P. Augustinianorum (prope Pontem S. Michaclis) e depois a data, posterior de dois anos. Inútil dizer que tais analecta não continham qualquer manuscrito de Adson de Melk." (p.12)

No conto de Borges: "Nas últimas páginas do volume XLVI achamos

13. 130RCil:S. Jorgec i uis. Fiçöes. p. 15. Usarcio mesmo procedimento para as cilaçöes do liviode boryes. 
um artigo sobre Upsala; nas primeiras do XLVII, um sobre Ural-AaltaicLanguages, mas nem uma palavra sobre Uqbar." (p.16)

E continua: "O volume que Bioy trouxe era efetivamente o XLVI da ANGLO-AMERICAN CYCLOPAEDIA. No antertosto e na lombada, a indicação alfabética (Tor - Ups) era a do nosso exemplar, mas, em vez de 917 páginas constava de 921 .

Essas quatro páginas adicionais compreendiam o artigo sobre Uqbar; não previsto (como terá o leitor observado) pela indicação alfabética. Depois comprovamos que nāo havia outra diferença entre os volumes." (p.17)

Vé-se que ambos contejam edições de um mesmo livro, as quais apresentam pequenas diferenças. A frase Eco "Como o leitor terá imaginado." e a de Borges " Como terá o leitor observado", quase idênticas, convidam o leitor a participar ativamente da busca em que o narrador se empenha. Este astucioso jogo de máscaras, típico de Machado de Assis, revela uma estrutura espelhada onde se cultiva o diálogo com o leitor in absentia. Tal leitor, o narratário, é uma construção do imaginário do autor, como se fosse um personagem e, portanto, faz parte da estrutura semiótica do texto.

O mistério do livro procurado desvenda-se por força de um fato inesperado, quando o narrador já se confessava cansado de procurar por ele e até mesmo em dúvida quanto a sua existência.

No romance de Eco: "E não me restavam senão as minhas notas, das quais, já começava a duvidar.

Se não tivesse acontecido algo novo estaria ainda aqui a perguntarme de onde vem a história de Adson de Melk. "A seguir o narrador conta que, por acaso, em Buenos Aires, em 1970, estando ele espiando nos bancos de um livreiro antiquário na Corrientes, caiu-lhe nas mãos um livro:

"Tratava-se da tradução do já inencontrável original em língua georgiana (TBILISSI, 1934) e ali, para minha grande surpresa, li copiosas citaçōes do manuscrito de Adson, salvo que a fonte não era nem o Vallet nem o Mabillon, mas o padre Athanasius Kirchen (mas qual obra?)." (p.13)

No conto de Borges: "Em marçó de 1941, foi descoberta uma carta manuscrita de Gunnar Erfjord, num livro de Hinton que fora de Herbert Ashe. O envelope tinha o carimbo de Ouro Preto; a carta elucidava completamente o mistério de Tlön." (p.32)

Além do paralclismo da citação de dados geográficos e datas, existe a curiosa coincidéncia de o narrador de $O$ nome da rosa encontrar a elucidação do mistério em Buenos Aires, numa livraria de Corrientes. Por 
ali já andara o personagem de Borges, ao tentar resolver o mistério de Uqbar:

"No dia seguinte, Carlos Mastronardi (a quem eu relatara o assunto) reparou numa livraria de Corrientes:e Talcahuano as pretas e douradas lombadas da ANGLO-AMERICAN CICLOPAEDYA...(p.19)

Evidentemente trata-se de uma citação intertextual que amarra muitos fios interpretativos lançados pelo autor italiano.

O fato de o narrador viajar, enquanto busca pistas do livro misterioso, revela-se um entrecruzamento de percursos. Enquanto o narrador de Umberto Eco vem da Europa e encontra o que procurava em Buenos Aires, o narrador do conto de Borges diz: "Em vão desarrumamos as bibliotecas das Américas e da Europa." (p.22)

O livro em que o narrador de $O$ nome da rosa encontra finalmente a solução do mistério chama-se Do uso dos espelhos no jogo de xadrez. Observe-se o inicio do conto de Borges: "Devo a conjunçăo de um espelho e de uma enciclopédia o descobrimento de Uqbar." (p.15)

Já Pierre Menard "escrevera": "um artigo técnico sobre a possibilidade de enriquecer o xadrez eliminando um dos peões da torre." (p.48)

De resto, o jogo de xadrez é uma metáfora do impulso lúdico, mas ao mesmo tempo extremamente racional, que impele o escritor na produção de um texto de estrutura complexa. No jogo de identidades e diferenças criado pelo escritor - apropriaçăo, paródia, estilizaçāo são conceitos sempre presentes.

Ao estudar a estilização, Affonso Romano de Sant Anna compara os efeitos literários com os musicais, dizendo que no "jazz": "há a possibiliclade de se introduzir um tratamento pessoal no discurso, numa atitude criativa constante. Neste jogo de identidades e diferenças em relação ao tema original, a peça clássica do "jazz" se mostra como um tabuleiro de armar." ${ }^{14}$

É cxtremamente curioso que, em 1985, noseu livro Sobre os espelhos e outros ensaios. Umberto Eco dedique um estudo ao método borgiano da conjetura, com o título "A Abdução em Uqbar." As reflexões teóricas deste estudo sobre Borges aplicam-se perfeitamente ao mecanismo fundamental na construção da trama de $O$ nome da rosa, ou seja, a arte das inferências. ou da abduçāo para Pcircc.

Por outro lado, o livro sobre o jogo de xadrez, onde o narrador de Eco encontra a solução do mistério sobre o manuscrito é: "um livro de Milo p. 39.

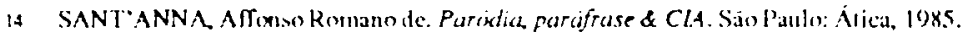


Temesvar." O narrador coloca-se então curiosamente como o próprio Umberto Eco, dizendo que já tivera ocasião de citar tal autor, em segunda mão "no meu Apocalípticos e Integrados, resenhando seu mais recente Os vendedores do Apocalipse." (p.13)

Nada encontrei a respeito na tradução brasileira do citado livro de Eco. Mais uma incógnita, mais uma pista falsa, entre as muitas artes e manhas do escritor italiano esmerando-se como se esmerara Borges em suas artimanhas bio-bibliográficas?

Como o leitor terá imaginado, por um desses acasos editoriais, a referida resenha existe na edição italiana, com o título "Da Pathomos a Salamanca". Traz, entretanto, muito mais do que eu imaginara.

Elaborar uma ficha pessoal de Milo Temesvar "não é fácil, como não é fácil estabelecer o campo de interesses de uma inteligência tão desordenada, inquietamente e imprevisivel", afinna Umberto Eco, explicando em nota de rodapé:

"Poiché, dopo la prima apparizione di questo scritto, un grosso editore e due critici acuti si sono messi a ricercare spasmodicamente le opere di Milo Temesvar, sarà onesto avvertire il lettore che il Temesvar non è mai csistito - come volevano suggerire le inverosimili informazioni bio-bibliografiche." ${ }^{15}$

Vê-se que Temesvar nunca existiu; é fruto da fantasia, como adverte Eco. Pergunto, fantasia de quem?

No primeiro parágrafo do scu trabalho, Eco evoca a circunstância que o levou a Temesvar:

"Durante un recente soggiomo in Argentina si impose all'attenzione degli studiosi con una memoria su Le fonti bibliografiche di J.L.Borges, che apparve filologicamente decisiva sino a che non fu confutata da un libello anonimo dal titolo Sull'uso degli spechi nel gioco degli scacchi.." ${ }^{16}$

Ressalte-se que Eco esteve na Argentina e o interesse dos estudiosos foi despertado por uma memória sobre as fontes bibliográficas, justamente

15 "Dado que, depois da primeira apariçăo deste escrito, um grande editor e dois critucos perspicazes puseram-se a pesquisar espasmodicamente as obras de Milo Temesvar, será honesto alerar o leitor que Temesvar nunca existiu - como queriam sugerir as inverossímeis infornaçóes biobibliogrificas." ECO, Umberto. Apocalitici e integrati. Milano: Tascabili. Milano, Tascabili Bompiant. 1978. p. 365 (a primeira edição da obra é de 1964).

16 "Durante uma recente estadia na Argentina, chamou a atençăo dos estudiosos com uma memória sobre As fontes bibliograficas de J.L. Borges., que pareceu filologicamente decisiva até ser

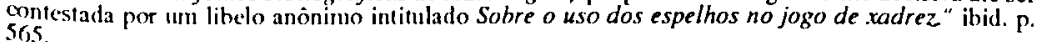


de Jorge Luis Borges, de autoria atribuída a Temesvar e imediatamente contestada por um libelo anônimo. E continua:

"Naturalmente l"autore di questo pamplhet era lo stesso Temesvar che perveniva cosi a confondere le idee ai propri lettori. ${ }^{17}$

O que temos entāo? Um autor que nunca existiu, cuja obra aparece num encontro de estudiosos na Argentina, chamando a atenção de todos com uma memória das fontes bibliográficas de Borges. A seguir, tal memória é refutada por um panfleto anônimo, mas de autoria do próprio autor inexistente, que, com isto chegava a confundir as idéias dos próprios leitores.

Temos pois a burla da burla, a farsa desmascarando a própria farsa, numa deliberada confusão biobibliográfica fascinante e instigante.

Teria Umberto Eco identificado no "caso" Temesvar a metáfora do universo ficcional borgiano ou do tipo de verossimilhança criada na introdução de seu próprio romance?

Temesvar estuda a gênese dos papéis culturais fictícios nas sociedades; propondo a seu modo, uma pesquisa sociológica: "a modo próprio perché propone delle succulente ipotesi interpretative, senza offire alcun elemento di verifica sul campo, ma in tale senso Temesvar si dimonstra coerente con le idee che a suo tempo aveva esposte in una memoria all'Accademia Sovietica delle Scienze, dal titolo La verifica come falsificazione dell'ipotesi." ${ }^{18}$

Ao elaborar seu modelo abstrato do "sábio de Salamanca" cujas referência históricas assumem valor alegórico, é evidente que Temesvar, com sua impostura filosófica, fascinou Umberto Eco.

A esta altura, sinto-me como o próprio narrador de $O$ nome da rosa, borgianamente mergulhada no jogo desta estrutura espetacular. Diante do tabuleiro armado, procuro prever as próximas jogadas do narrador. Mas, de um jogo como este, segundo o próprio Eco, não há saída, visto ser ele regido por três principios lógico-antropológicos indiscutiveis, que são: " 1. Para cada afirmaçāo feita num lugar, é possivel encontrar uma contrária feita com antecedência em outro lugar. 2. Para cada afirmação feita em determinada época existe um fragmento dos pré-socráticos que a antecipa. 3. Toda

17 "Naturalmente o autor deste "pamplet" era o próprio Temesvar que chegava desse modo a confundir as idéias dos próprios leitores." ibid. p. 365

18 "a seu modo porque propōe suculentas hipöteses interpretativas, sem oferecer nenhum elemento de verificação no campo, mas neste sentido Temesvar demonstra-se coerente com as idèias que em seu tempo havia exposto em uma memória a Academia Soviética das Cièncias, com o titulo A verificaçāo como falsificaçāo das hipóteses." ibid. p. 366 
afirmação de consenso a uma tese, se expressa por várias pessoas, torna as opiniões dessas pessoas definiveis como "afins" ou "conformes".

Evidente que o tal jogo referido pelo autor é o jogo da "moda cultural" na Itália, mas o tipo de raciocínio envolvido no processo, permite a associação com a estrutura labiríntica de seu romance. Presa na teia tecida pela intertextualidade vertiginosa, lembro Roland Barthes:

"TEXTO quer dizer TECIDO; mas não enquanto até aqui este tecido foi sempre tomado por um produto, um véu acabado, por detrás do qual se conserva, mais ou menos escondido o sentido (a verdade); nós acentuamos agora, no tecido a idéia generativa de que o texto se faz, se trabalha através de um entrelaçamento perpétuo; perdido neste tecido - nessa textura - o sujeito desfaz-se, como uma aranha que se dissolvesse a si própria nas secreçōes construtivas da sua teia. ${ }^{20}$

No centro do labirinto de signos criado por Eco, inspirado em Borges, vejo que é preciso retomar o fio interpretativo do presente trabalho.

Quanto ao fato da autocitação, Borges já o fizera em "Exame da obra de Herbert Quain": "Da terceira (narrativa) 'The rose of Yesterday', cometi a ingenuidade de extrair "As ruínas circulares", que é um dos contos do livro O jardim dos caminhos que se bifurcam." (p.83)

Tal procedimento é reiterado em livros diferentes, onde Borges sempre mistura obras e autores reais, inclusive ele mesmo, com obras e autores fictícios, com o objetivo de surpreender e confundir o leitor. Acrescentem-se os prólogos e epílogos, as escrupulosas anotações de rodapé e as citações, com que o escritor se deleita. $O$ caráter paradoxal de suas narrativas e acentuado, dessa forma, em termos da pseudo-autenticidade das informações. Neste sentido, o título de seu livro Fiç̧ões é perfeito, podendo ser lido na acepção normal do termo ou como referência metalingüística aos procedimentos referidos acima. Deles o autor argentino mostrava-se perfeitamente consciente; assim como Umberto Eco, que usa as distorções intencionais e as atribuições falsas como recursos produtivos na fiç̧ão.

No Prólogo de Ficçōes Borges coloca:

"Desvario laborioso e empobrecedor o de compor vastos livros; o de explanar em quinhentas páginas uma idéia cuja exposição oral cabe em poucos minutos. Melhor procedimento é simular que estes livros já existem e apresentar um resumo, um comentário." (p.13)

19 ECO, Umberto. Viagem... p. 206

20

BARTHES. Roland. O prazer do texto. Lisboa: Ediçöes 70, p. 112 
Observe-se que foi exatamente o procedimento escolhido por Umberto Eco no "caso" Temesvar, ao questionar a própria questão da verossimilhança dos dados persuasivos postos em jogo. Em verdade, $O$ nome da rosa constrói-se em termos de uma espécie de retórica da verossimilhança. Dentre os elementos persuasivos utilizados pelo autor, o estratagema do livro inventado ou aquele do documento encontrado revelam-se ideais, sendo também utilizados por Borges. Desse modo, o escritor incita o leitor a acreditar ou a jogar com ele, preenchendo os espaços de "abertura" - entendida esta como ambigüidade fundamental da obra estética.

Os textos de Eco ou de Borges, vistos como obras-abertas, dão margem a certos tipos de associaçōes e à livre e ativa inserção de dados do repertório do leitor. Este, diante da inesgotabilidade de sentidos dos problemas artísticos, sempre propostos, mas nunca resolvidos, deve participar do jogo como co-autor, na construção de sentidos que se pluralizam.

O fato de eleger outro(s) texto(s) como instigação já demonstra uma valorização: a seleção dos textos com os quais dialogar já é, em si, indice de valor conferido. Barthes indaga:" que textos aceitaria eu escrever (reescrever, desejar, avançar como uma força neste mundo que é o meu? O que a avaliação encontra é este valor: aquilo que hoje pode ser escrito (reescrito): o escriptivel." ${ }^{21}$

Uma vez que os livros já escritos fazem parte da própria arte de viver, a arte literária, melhor que as outras, traz em si a força da intertextualidade. Desnudando o processo e intensificando-o, o prefácio de Umberto Eco, torna-se inclassificável, hibrido, paradoxal. Quebra-cabeça magistral, assim como o restante do romance, exige a participação crítico-criativa do leitor/co-autor, na construção de sentidos que se pluralizam.

O mesmo acontece com os textos de Borges. Ler a escritura borgiana nas entrelinhas do romance de Eco é participar com seriedade do jogo proposto.

Dos choques, dos deslizamentos de sentimentos, das interpenetraçōes signicas, do entrecruzamento de lances possiveis de dados, deste fogo cruzado enfim, o leitor só poderá sair ganhando. Sua participação lúdica e ao mesmo tempo lúcida, numa relação fruitiva densa, próxima à co-autoria, só poderá ser extremamente gratificante.

21 BARTHI:S, Roland. SZ. Paris: Seuil, 197-0. p. 11 


\section{RESUMO}

Tanto O nome da rosa, romance de Umberto Eco (de 1980) quanto os textos de Jorge Luis Borges, bem anteriores (Fiç̧ōes è de 194 1), apresentam fortes marcas intertextuais. Ao aproximá-los, pretendo captar certos ecos borgianos no romance do escritor italiano.

Utilizando-se das alusões, das metáforas intertextuais, dos recursos palimpsésticos, Eco disseminou ao longo do seu romance - um intertexto por excelência - uma série de indices para a compreensão de sua estrutura e mesmo para sua interpretação. Seu enunciado remete a outros, numa cstrutura labirintica, onde a multiplicidade de caminhos intertextuais faz do texto uma escritura complexa, opaca, infinita...

Este estudo prende-se à introdução do romance de Eco, "um manuscrito, naturalmente", confrontando-a com textos de Borges, especialmente de Fições. Remete ainda ao pensamento teórico dos dois autores. 